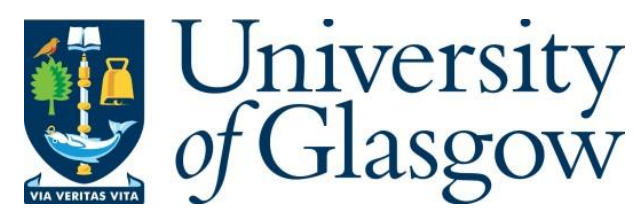

Humphries, J. (2018) Intimacy, autonomy and (non) domination. Journal of Applied Philosophy, 35(2), pp. 399-416.

There may be differences between this version and the published version. You are advised to consult the publisher's version if you wish to cite from it.

This is the peer reviewed version of the following article Humphries, J. (2018) Intimacy, autonomy and (non) domination. Journal of Applied Philosophy, 35(2), pp. 399-416, which has been published in final form at

http://dx.doi.org/10.1111/japp.12218. This article may be used for non-commercial purposes in accordance with Wiley Terms and Conditions for Self-Archiving.

http://eprints.gla.ac.uk/161836/

Deposited on: 6 July 2018

Enlighten - Research publications by members of the University of Glasgow http://eprints.gla.ac.uk 


\section{Intimacy, Autonomy and (Non) Domination}

\section{Abstract}

Accounts of autonomy which acknowledge the importance of non-domination - that is, of being structurally protected against arbitrary interference with one's life - face an apparent problem with regards to intimate relationships (whether romantic or otherwise). By their very nature, such relations open us up to psychological and material suffering that would not be possible absent the particular relationship; even worse, from the non-domination point of view, is that this vulnerability seems to be structural in a way exactly analogous to (for example) workplace or social domination. If being powerless to prevent an employer causing me harm constitutes domination at work, then what relevant differences can support the intuition that being powerless to prevent my partner causing me comparable pain is not autonomy-hostile? I argue for the reassuring view that the obligations and possibility of pain arising from such relations aren't necessarily dominating; they would be so only if we believed that any obligation we have not explicitly agreed to is a restriction on our autonomy, and that is false. I conclude with a note of caution: even though intimate relations aren't necessarily dominating,they will often be contingently so if they take place in a wider social context of domination - such as that which we currently inhabit.

\section{Introduction}

It is relatively uncontroversial in contemporary political philosophy to argue that interpersonal relationships can play a vital role in the autonomy of agents; that is, using for the moment the barest notion of autonomy, relationships with others can and do form part of our leading lives that are in some important sense "our own". After all, intimate friendship and romantic relations are clearly involved in the deeply-held values or desires of many such agents; whether we think that intimate relationships are constitutive of autonomy, or fulfilling the desire to have them makes us autonomous, or any number of proximate alternatives, the idea that our engagement with others can itself make us more autonomous (or indicate our autonomy, etc) is not a fringe notion. ${ }^{1}$

On the other hand, feminist philosophers in particular have signalled that personal relationships can be - and often in fact are, especially for members of oppressed groups barriers to autonomy. ${ }^{2}$ The aphorism that the personal is political captures the thrust of this point; no amount of formal or legalistic equality will secure the autonomy of an agent whose life is structurally prone to being controlled by other agents, whether this control is exerted through discriminatory employment practices, gendered power imbalances in family structures, or within intimate romantic relationships. On this eminently plausible thesis, my self-direction being subverted because my partner or partners possess social status or privileges which I am denied thanks to (for example) my gender identity, and use this status to interfere with how my life goes, is no less a matter of political concern than would be the legal abrogation of my rights on the same basis.

This observation has a worryingly persuasive corollary which is the focus of my paper: if the structure of intimate relationships can render them loci of oppression regardless of the participants' intent or integrity, then what philosophical grounds do we have for thinking that any relationship might escape being such a locus? The challenge to our widely-held assumption that, as Friedman puts it, "mutuality, equality and personal autonomy can 
occur in romantic love relationships" is a serious one. ${ }^{3}$

In particular, the problem here is how best to account for the possibility that there are interpersonal relations and obligations which are hostile to autonomy, without resorting to the kind of hyper-individualism that would suggest anyone in a committed relationship is made less autonomous by that relationship. Although there are, to the best of my knowledge, fairly few card-carrying Randians in the discipline, the idea that autonomy really is incompatible with intimate relationships is not a mere stalking-horse. The argument can take two forms: the right-libertarian or Objectivist thought that any and all obligations we haven't freely entered into make us less autonomous, and the pluralist thought that while autonomy is a value, it is not the only or most important value, and can clash with other crucial values - such as the value of intimate relationships. ${ }^{4}$

Section 1 of the paper sets the problem up in more detail, providing a fuller account of the notion of autonomy being assumed in the paper (and a brief sketch of why I think this account is plausible) In section 2 , I provide a plausible explanation for the worry that relationships may make us less autonomous: namely, that we are concerned about domination and vulnerability. Section 3 draws parallels between worries about domination in romantic relationships and domination in other contexts (such as employment), as well as arguing against several possible ways of conceiving the problematic parallels. In Section 4, I argue that that putting these mistaken conceptions to rest gives us a way out of the worry that intimacy per se is dominating and thus autonomy-hostile and suggest that a similar problem (and solution) faces accounts of freedom as non-domination, concluding with some cautionary remarks about how intimacy may nevertheless be used as a mechanism for domination in precisely the way that feminists have warned about - but perhaps on an even wider scale.

\section{Autonomy, Domination and the Problem from Intimacy}

The heart of the issue, it seems to me, is one of domination. Intuitively, non-domination is important for autonomy - though an agent may obviously self-direct, make authentic choices and so on under conditions of domination, as a rule of thumb dominated agents are very likely to be less autonomous than non-dominated agents. The worry is that something about intimate relationships renders us dominated, and therefore less or nonautonomous, without these relationships being dysfunctional in any of the multifarious ways that such relationships can be.

My argument is that although there is obviously the potential for harm in a relationship, a significant feature of non-dominated agents is their non-vulnerability; that is, that they stand in relations which are by design hostile to malevolent interference in one's life. Thus, while the question is an important one, we are not forced to answer that just being in a committed relationship makes us vulnerable in the relevant ways, since intimate (and nondysfunctional) relationships are hostile by design to interference of this sort. Indeed, insofar as these relationships allow us to extend the scope of valued self-direction and pursue deeply-held goals, they are often significant constituents of our autonomy.

There is a fairly important clarificatory point to be made at this juncture. The extent to which one holds that autonomy is possible under conditions of domination is dependent on how one conceives of autonomy. Primarily internalist accounts which suggest that 
autonomy is a matter of having one's desires lined up correctly or of making authentic choices will be less concerned than externalist, and particularly relational, accounts such that found in Oshana, where the relations one stands in are constitutive of autonomy or heteronomy. ${ }^{5}$ On the latter account, to be dominated is to be so much less autonomous.

I presume something very similar to the social-relational account throughout this paper, which means that I am (as, I think, is Oshana) committed to the view that domination always costs us at least some measure of autonomy - this is controversial insofar as it suggests that, for example, folk under conditions of oppression are blocked from maximal autonomy, a claim which is rejected by, for example, Meyers. ${ }^{6}$ As it happens I think the claim is highly persuasive - how can we be in control of our lives if they're being run according to the whims of another? - but its opponents could surely still accept the more modest claim that domination is not generally a good thing (even while defending their claim that some agents may by more autonomous in virtue of their response to domination).

Thus, while the issue arises out of considering non-domination in the context of a specifically relational theory of autonomy, this problem should also be of interest to anyone who is generally sympathetic to non-domination as a value (whether as a constituent of autonomy or, as discussed at the end of Section 4 , of freedom). ${ }^{7}$

\section{The Problem: Alice and Bryony}

To begin, it is worth trying to capture the problem in as intuitively straightforward a fashion as possible. Imagine for a moment some agent, Alice, who sees herself and is seen as an independent source of values, someone who by and large decides on the direction of her life according to those values. She is, most of us would agree, autonomous. Now imagine that she meets a second agent, Bryony, and eventually becomes romantically involved with her. Now much of Alice's self-direction is shaped by Bryony's wishes; Alice's weekend plans, holidays, even career may no longer be hers to decide upon. She is, it would appear on the face of it, non-autonomous.

Well, we might think, so it goes; people do unpleasant things to each other all the time, and the existence of controlling partners is not an obvious problem for autonomy. After all, there are folk in the contemporary equivalent of chattel slavery, but we don't tend to think that this means autonomy isn't valuable. If anything, it might seem to militate in the other direction: overbearing partners, analogously to slave-holders, are a concrete example of why we ought to be concerned with autonomy, not an example of why we should be concerned that autonomy - or intimacy - is disvaluable.

But the problem is not, or not only, one of the overtly abusive or manipulative partner. There is no need for Bryony to act malevolently for her to influence Alice and, further, not even any need for her to try and influence Alice. It is trivially easy to imagine a situation where Alice realises that she must give up something valuable in order to remain with Bryony: to use a hackneyed example, she can either take up a long-pursued job which will necessitate the end of the relationship, or she can abandon the job for the relationship's sake. Despite Bryony's manifest innocence here, it looks like her presence is what causes Alice to face significant material or psychological suffering in the course of her selfdirection; it is the existence of the relationship which makes Alice's choice so difficult, and, generally, we regard obstacles to self-direction as being at least prima facie hostile to autonomy. 
In other words, it looks like Bryony has undermined Alice's autonomy, and if we are concerned with autonomy, we should advise Alice to end the relationship. Curiously, it also looks on this picture as if domination is reflexive and we should give Bryony the same advice - in other words, if Alice loves Bryony and vice-versa, such that each of them is vulnerable in the way suggested above, Alice and Bryony are dominating each other in exactly the same way and at the same time. ${ }^{8}$

This, I take it, is not a response that many readers sympathetic to social views of autonomy will want to adopt; it commits us to the view that intimacy per se is a threat to autonomy and suggests exactly the kind of individualistic account I rejected at the start of the paper. In later sections I offer an attempt to avoid this disheartening conclusion. First, however, it will be useful to show how it may seem to follow from plausible thoughts about what is required for autonomy.

\section{Non-Domination and Non-Vulnerability}

My contention here is that we are primarily concerned by the Alice-Bryony case insofar as it suggests that Bryony stands in relations of domination to Alice. Since the autonomous agent cannot, on my view, be dominated, we must conclude that Alice is non-autonomous (or, again, less autonomous); and from these premises, it seems that the reason Alice is non-autonomous is precisely because of her relationship with Bryony. Further, we cannot evade the problem by insisting that Bryony must be acting maliciously or manipulatively. If there is no way to refute the claim that any and all intimate relationships must involve domination, then we are forced to conclude that such relationships are indeed hostile to autonomy. In this section, I go into more detail about domination and vulnerability as they relate to autonomy, and provide several examples of domination in contexts other than intimate relationships. By showing that our worries about autonomy and relationships are roughly parallel in form to our worries about domination in (for example) the workplace, we will have the basis for addressing those worries in similar ways.

\section{Non-Domination and Autonomy}

The importance of non-domination is usually emphasised by considering cases where one agent has considerably more freedom of action than another, and yet seems no more meaningfully free or (in our case) no more autonomous. Take the following example from Pettit: some ancient Roman aristocrat has two slaves, one of whom constantly resists and opposes the slave-holder's wishes, while the other is particularly good at judging their moods, placating them, and so forth. The latter slave is rarely beaten, and often gets time off or some extra allowance; but though they might have a much greater practical realm of self-direction, and may even be very unlikely to suffer the "usual" punishments or repressions of slavery, it strikes most of us as very implausible to claim that they are consequently less enslaved. ${ }^{9}$

Pettit argues that the primary reason for our unease about assigning a greater level of freedom to the slave who accurately predicates the slave-holder's wishes is that, while they might have a higher level of non-interference than the other slave, they are equally prone to interference - that they get, say, an extra two hours' a day free time is a concession made entirely at the whim of the slave-holder, and should the whim cease then the extra free time vanishes. The power of the slave-holder over the slave's lives is 
arbitrary; there is no possibility for the slaves to contest this power, but only to try and deflect it in certain ways. As such they are equally dominated, their self-direction extended or limited solely according to the wishes of another.

We might also think of this in terms of the enslaved agents having only as much power over their lives as the oppressor is willing to let them have. The fact that one agent is (as it happens) granted more power than another doesn't make the former more autonomous, for the reason that - excepting the requirements of morality - our realm of self-direction should not be determined by others and certainly not determined by another's passing moods. It is plausibly this which accounts for our intuitions that the second slave is no more meaningfully free than the first. ${ }^{10}$

While Pettit's idea of non-domination as a (structurally guaranteed) freedom from arbitrary interference with one's life greatly informs the conception I put forward here, there are several differences which - while not likely to affect this argument too much - are worth making clear before continuing. ${ }^{11}$ First, Pettit seems on the whole to be concerned with legal domination, whereas it strikes me that the law is at most a means of preventing or enforcing some kinds of domination, and that we should be on the lookout for all kinds of structural or institutional (non) domination rather than 'merely' statist domination. Secondly, a closely-regulated structure of interference with one's life, according to wellknown rules grounded in theoretically-consistent bases, may (or may not) prove hostile to one's autonomy or freedom, but it seems odd to call it arbitrary. As such, I will refer to unjust rather than arbitrary interference. ${ }^{12}$ This modification does not seem to me one that should offend anybody with a sympathy for non-domination as a value, nor one that renders the problem idiosyncratic; however, readers are welcome to think of my problem here as being one for "social" domination rather than the more narrowly legal conception of domination, if they think the distinction to be vitally important. ${ }^{13}$

On my view, an agent is non-dominated if she stands in relations such that she can, to borrow Marina Oshana's characterisation, "determine how she shall live in a context of at least minimal social and psychological security". ${ }^{14}$ That is, she cannot be constantly looking over her shoulder for death squads or roving bandits (nor forced to banditry herself), nor can she be under overwhelming pressure to live in a particular fashion lest she be ostracised, suffer material harms, and so on. Leaving aside the relational aspect for now, this non-domination has two requirements: that we be non-vulnerable, and that this non-vulnerability be based around recognition respect. Only the first requirement is relevant here, so I focus on it exclusively.

So, if non-vulnerability is a requirement for non-domination, what is it to be nonvulnerable? Return to the slave cases: whether or not the slave-holder is actively interfering with the slaves' lives, they have no recourse against him doing so. While appeasing the slave-holder might incline him not to interfere, it acts as no kind of preventative against him interfering. By analogy, I could try to prevent someone from shooting me by verbally encouraging them not to or by taking the gun off them, but in the first case I am still vulnerable to being shot even if I successfully prevent it from happening at this moment. Vulnerability in the relevant sense should be construed as standing in relations (or being enmeshed in structures, etc) that systematically open one up to unjust interference by another, and so to be non-vulnerable is to stand in relations such that there is some effective recourse against unjust interference. 
require the absence of dominating relations? Conceptually, I suppose, this is possible. If I am the only person on a desert island, or the last person on Earth, then it would indeed seem odd to say that I was vulnerable to domination because of the lack of certain social relations. The vast majority of us, however, stand inescapably in social relations of some sort or another, and so the absence of dominating relations must mean the presence of non-dominating ones (and vice versa). If I do not stand in relations of domination, I cannot simply stand in no relations or somehow 'domination-neutral' relations, and so - barring outlandish desert island cases - non-domination does require that certain relations obtain.

Take an example which contrasts with the slave case, that of a unionised worker in a society with fairly solid protections against exploitation. There is obviously still the possibility that folk will try to unjustly interfere with my life: the bosses might prevail on me, through threats of dismissal or the like, to cover a colleague's shift or work overtime for free. However, I am manifestly not vulnerable in the same ways as an enslaved agent is. Partly, of course, this is because the bosses' scope to interfere is much narrower than in the slavery case: but this is itself evidence of a certain level of non-vulnerability, since unlike the enslaved agents I can walk out on a job without fearing imprisonment or starvation. Apart from the ability to walk away from such interference, the non-vulnerability is also a matter of my being able to defend against it: as stipulated, there are ways (internal grievance procedures, industrial action or tribunals) in which I can prevent the attempted coercion. It is therefore not the case that I stand in relations (or within a structure, etc) which make me systematically prone or open to exploitation or harm; there may be individual or indeed collective attempts, but such attempts are made in the teeth of institutional and social rules and norms, not through such norms.

To recap: non-domination as a value, and as a constituent of or contributing factor to autonomy, requires that we stand in relations such that we will be effectively defended against attempts to arbitrarily or unjustly interfere with our lives. Social structures should not be arranged so that, for example, we can be systematically forced to choose between giving up some valued (and morally permissible) activity or facing serious harm, or made to continue some labour we find deeply distasteful or at odds with our self-conception on pain of punishment. These relations are complicated and not comprehensive; I may be non-dominated in education but dominated in the workplace and so on, but the less vulnerable I am the less dominated I am. Non-vulnerability is not sufficient for nondomination (because of the recognition respect requirement I set aside earlier), but it is necessary.

When we are concerned that Bryony makes Alice less autonomous, I think we are at bottom concerned that Bryony dominates Alice in a way which closely parallels (if it isn't actually isomorphic to) the way we may be dominated in other realms of life. In the next section, I draw this conception of the worry out more fully, and rule out several ways in which we might think that the relationship is dominating.

\section{Parallels, Chimerical Problems and the Start of a Solution}

The non-vulnerability condition invites a number of lines of argument about its feasibility for the power and authority conditions of autonomy which I do not address here, instead focussing on one particularly problematic concern: namely, that requiring us to stand in relations which militate against our having to face harm and distress also seems to require 
that we either give up close interpersonal relations, or at the very least look on them as threats to our autonomy.

The objection would take something like the following form: I have claimed that we are vulnerable insofar as our self-direction is prone/susceptible to unjust or arbitrary interference - paradigmatically, if we would (for example) have to give up a valuable activity or suffer serious emotional or physical harm at the hands of another. But this seems to be precisely the kind of problem that affects intimately-related agents with divergent or conflicting values. If I am faced with the prospect of passing up valued employment because the alternative is the breakdown of an intimate relationship, then it looks very like I must choose between self-direction and serious emotional harm. ${ }^{15}$

It is worth getting clear on exactly what the objection involves before moving to respond to it. First, we should not confuse our vulnerability to emotional pain with what I have defined as vulnerability. I am, in the ordinary language sense, vulnerable to a swift stab in the eye, but this doesn't mean that I am vulnerable in the sense relevant to worries about domination. Similarly, we ought not allow the usual connotations of 'vulnerable' with regards to emotion to colour our view here: anyone in a committed relationship, plausibly, is more vulnerable to heartbreak than anyone who is not, but this should not simply be taken as equivalent to their lacking non-vulnerability in my sense.

A further thought arises from that clarification. It seems that a conceptual requirement of a deep relationship is the possibility of its ending. If there's some set of relations or conditions that make up a deep relationship, then it must be possible for us to fail to meet them. In just the same way, in order for "being a teacher" to be a meaningful concept, there has to be the possibility of failure to be a teacher or else everybody would be a teacher and the word would have no comprehensible extension.

So we cannot require that deep or committed relationships be ever-lasting; it can't just be the possibility that they end which has the (putative) effect of making us problematically vulnerable. Rather, it seems to be in the yoking of our well-being to that of another. The self-direction threatening vulnerability that I spoke of earlier must, it would appear, lie in the fact we are at risk of fairly serious psychological or material damage if we self-direct in certain ways - to a significant extent, how our life goes is beyond our control.

One parallel with the workplace example that lends credence to this worry is the structural or relational nature of the vulnerability. We are vulnerable to domination in the workplace insofar as there is no way even in principle for us to avoid one harm without suffering another, so that, for example, the relevant structures that the agent stands in gives her the choice only between acting in a way that contradicts her values or selfconception, or of serious harm (which may be the harm of acting in a different way that is inconsistent with her values, or may be direct emotional or physical harm). There is, to restate the point, no structure or set of relations which would defend her against this kind of coercion, and so she is vulnerable to domination even if not "actively" dominated. If, on the other hand, any attempt to force this choice upon her will be met with effective resistance, then she is not vulnerable even if it is still possible for someone to make the attempt. The relations that she stands in are not of the kind where self-effacement or harm is "built-in" or supported, so although there is (as there almost always will be, the cynic chimes in) the potential for some other agent to try and dominate her, these relations militate by design against the attempt being successful. 
So the objection is not that the relationship might end and we might thus be hurt, nor even that by being emotionally close to another (or others) we make it possible for them to harm or coerce us. After all, it will still be true of non-dominating labour relations that we have made it possible (or just easier) for a colleague to try and harm us in the sense that they couldn't make the attempt if we hadn't taken the job. Rather, the problem is that intimate relationships look to make us structurally vulnerable: there is no "third option" to take when confronted with, say, a choice between moving across the globe to pursue a valued career at the cost of a deep personal relationship or remaining in an unfulfilling (alienating, exploitative, etc) job in order to preserve that relationship; no tribunal we can appeal to that will resolve the dilemma.

There is an objection to be fielded here. Is the problem really as stark as I have made it out to be, or is there some implausible "philosophers have arranged it that..." thoughtexperiment gerrymandering going on? In particular, the critic may attack my claim that there is no third option; perhaps I can find a similar job closer to home, or we can try to make a long-distance relationship work, or some other compromise solution. ${ }^{16}$

It seems undeniable that in many real-world cases, the option set will not be of the simplistically binary form given previously; we almost certainly would in fact try to find an alternative to the pair of unpalatable possibilities, and we may sometimes be successful. But in lots if not most of these actual cases, we are likely to be unsuccessful in our pursuit of a satisfactory solution - particularly, and in another parallel with workplace vulnerability, depending on the social structures we are already enmeshed in. Firstly, long-distance relationships are notoriously difficult, and prone to breaking down; if Alice's status is such that regular travel to see Bryony is economically implausible (whether directly through the cost of flights etc, or because it's impossible to take the required amount of time off work), then maintaining that relationship becomes more difficult than it would already have been. In a similar fashion, it is far from clear that alternative jobs are usually available in the actual world - to give a pertinent actual case, my options when it comes to jobs in academic philosophy are severely limited by a number of factors (and again, depending on social and economic context, my options may be more or less limited independent of things like my qualification for a particular post), and giving up on the career would be a serious blow; it is entirely possible, and depressingly likely, for me to be presented with exactly the kind of "this job, no job or a disvalued job" choice that we imagined Alice facing. Secondly, these compromises are just that - non-ideal solutions; a limitation of Alice's selfdirection because of an apparent vulnerability that would not exist if it were not for her relationship with Bryony.

The importance of background social and economic conditions will be explored more fully in the next section; for the moment, the key point is that the critic's objection that I have made the problem seem worse than it is does not - at least, for most people at most times - hold.

Of course, one could just bite the bullet here and concede that we are vulnerable to those we are intimately involved with, but such a response would lead us directly into an individualist, almost Randian and assuredly anti-social view where the presence of or attachment to others is a constant danger to our self-direction, and the more intimately we are involved with them the less likely we are to lead autonomous lives. ${ }^{17}$ This, though, is a path that should worry anyone concerned with autonomy, freedom, and particularly with domination - given the social context of our investigation, where we are at least partly aiming to reconcile the importance of non-vulnerability with the value of human interaction 
and relationships, to adopt an account that casts intimacy as a compromising weakness is more or less to throw up one's hands and admit defeat. ${ }^{18}$

In order to do the work we want it to in explaining and illuminating the value of selfdirected lives, an account of autonomy surely ought not to say that agents are made less autonomous simply by dint of being in intimate relationships. What is required is thus a way to show either that vulnerability of this sort is relevantly different to, say, the vulnerability to being exploited at work, or that we have defences against relationship domination just as we do against workplace domination.

\section{Non-Domination, Non-Vulnerability and Autonomy}

In responding to the objection from intimacy, it will be helpful to consider a point made by Jay Wallace in his paper on obligations of intimate relationships: there are always normative considerations which will result in agents' being "not completely free to chart their course through life on their own terms". ${ }^{19}$ That is to say, there is invariably the potential for there to be moral or pragmatic reasons not to pursue some course of action we might deeply desire to pursue - but this is not in itself a limitation on our autonomy (it may perhaps count as a limitation on freedom, but that is another matter). My being morally and perhaps legally bound not to kick older folk in the kneecaps does not represent an arbitrary or unjust interference with self-direction, so in order for a relationship's generating obligations upon me to make me vulnerable in the relevant sense, the obligations must be unjust or arbitrary. With this thought in mind, the antiRandian path opens up.

Take the plausible claim that there are going to be some obligations which are constitutive of a loving relationship - for example, the obligation to provide support and comfort when the significant other(s) are unhappy. ${ }^{20}$ If this is correct (and I assume that it is from here on out), and if it is the case that forming loving relationships is at least one type of relation that can be constitutive of autonomy, then we must conclude that these kinds of obligations are, perhaps indirectly, themselves autonomy-constitutive. ${ }^{21}$ This surely isn't a wild claim: I may have new obligations as a professional musician that I didn't have as a garage band member, but - at least insofar as these obligations are a required part of a musical career, and that pursuing this career is part of my valued self-direction these obligations make up part of my (incompletely) autonomous life; this claim, and the general point that obligations can be part of our pursuing autonomous lives, seem fairly innocuous to me.

Note, here, that there's at least some potential for psychological (rather than material) vulnerability: I would, presumably, be deeply unhappy to fail in my dream of conquering the music business. But without the possibility of failure, the success would be meaningless, and we can stipulate that this failure is not the result of unjust or arbitrary interference in my life, so it now looks as if the possibility for emotional damage is one which is, at least in my case, a required part of the relation. It would be sad, unpleasant, sub-optimal etc for me to fail, but not unjust or arbitrary, so the necessary risk of pain is not vulnerability in the relevant sense. If I have to choose between, say, giving up a valued job offer or giving up a valued relationship, either option is going to cause me pain, but then that's surely true by virtue of my valuing them - an exclusive choice between two valued options must involve some regret, it seems to me - and it is absurd to think that the autonomous agent is by 
definition able to obtain everything they value. A painful choice may be the result of unjust coercion, but it may also be a blameless result of our having complicated and sometimes inconsistent sets of desires.

The story so far, then, is that neither the generation of obligations by, nor the possibility of emotional harm resulting from, standing in particular social (or economic relations) will make these relations of vulnerability, at least absent injustice or arbitrariness. It is not merely being more heavily obliged that makes an agent heteronomous or dominated; the nature of the obligations are the key, not their mere presence.

Our ruggedly individualist critic is therefore left with only one option to press the claim that committed relationships may render us vulnerable and thus dominated: the notion that, in some sense, we do not freely enter into the varied obligations generated by deep relationships. Our consent is never obtained, and so any obligations placed upon us are dominating.

It is, as the objection might run, as if I thought I was becoming a primary school teacher but have instead been manoeuvred into a job teaching at secondary school - or, more to the point, as if I leapt into either job without any idea what obligations might be involved, and am now bound by duties and risks I could not have been expected to foresee. After all, we surely cannot wave through just any obligation or interference on the basis that the person(s) involved freely entered into the relationship; there is nothing about asking someone out for a drink to suggest that we thereby commit to radically altering or abandoning our values and long-term goals.

To again draw on Wallace's paper, the duties of relationships do not simply fall upon us wholesale when we pass some specific checkpoint; "it is partly up to individuals to determine for themselves the exact contours of the obligations they fall under in so far as they participate with each other in relationships of love". ${ }^{22}$ If my partner has explained to me that they deem it vital for me to $x$, then either I can refuse to $x$ - with whatever consequences that might entail - or I can accept the obligation to $x$. If I accept the obligation, then ceteris paribus I have consented to it. ${ }^{23}$

Now, of course, if the consequences of my rejecting $x$ include being, say, savagely beaten or publically humiliated, then the consent is very dubious and I am vulnerable - but I am vulnerable precisely because of an injustice that should not be present in a loving relationship. There is no room for a situation where we can be in an intimate, nondysfunctional relationship and have intolerable and unjust burdens put on us by the other(s), because the two are simply inconsistent.

To draw another parallel with employment relations: there is no realistic way to guarantee that I won't come into work and be assaulted by an enraged student, colleague, or administrator, but the relations I stand in are (supposed to be) hostile to that sort of thing, so that such an attack would be a deviation from, and guarded against by, the labour relations I stand in. In other words, I cannot be sure that no-one is going to bean me with a brick when I walk into the office, but I am non-vulnerable if I can be sure that such an action would be seen as unacceptable and entirely inconsistent with the employment relations I stand in, and that I will be supported in attempting to fend off or seek restitution from my attacker. My general moral rights are socially defended, and I am non-vulnerable and thus non-dominated, insofar as somebody's attempting to crack my skull with stray masonry is regarded as beyond the pale for workplace relations. 
We can now shift the argument back to the confusing and unsettling realm of love, with the following articulation: standing in special obligations to another does not make us vulnerable, all possibility of emotional pain and limitation of self-direction accounted for, unless these obligations have simply been imposed by fiat or involve an unbearable cost and it seems very odd to say that someone could genuinely share intimacy with (as opposed to obsessing over, etc) someone upon whom they shovel arbitrary or unjust obligations. ${ }^{24}$ So in the one apparent case where an intimate relationship does seem to damage or threaten autonomy, the correct diagnosis is that the relationship is dysfunctional in other ways, not that its being an intimate relationship is the problem.

Similarly, it is possible that someone I am in a deep relationship with will act badly betray trust, attempt to manipulate or emotionally blackmail me, and so on. However, this is in the first instance to act immorally and in breach of "duties of love" in any case: we are not vulnerable because we're in an intimate relationship, but because we're in a dysfunctional relationship, or just in a relationship which is experiencing more or less temporary malfunction. Moreover, the other person(s) is/are in no position to force my acquiesence to continued interference of this kind, so the structural aspect of domination is not present.

In order to draw out this second point, return to the example of someone who jumps me with a brick in the office - for all that it will be deeply unpleasant, I am not vulnerable in the relevant sense because, as it were, they only get one shot at me; I don't have to plan my work life around evading their continued assault, and there is no institutional reason why anyone else should take over where they left off. I am under no compunction, essentially, to choose between self-direction and welfare. Similarly, the person who acts badly and causes me emotional damage is not in a position to do it again unless I allow them to. Whilst it's obviously possible that I allow them to because of some psychological hold they have over me, this sort of malevolent interference means I'm already non-autonomous or less autonomous, so the structural, "built-in" possibility of unjust or arbitrary interference does not exist here. ${ }^{25}$

To recap my argument in this section: the mere fact that relationships may cause pain does not render us (relevantly) vulnerable, because - given the kinds of creatures that humans are - we are at risk of pain or suffering in indefinitely many activities. It is true that intimate relationships make us particularly easy targets for emotional suffering, but without that risk we would not get the valued relations, just as we cannot (currently, at least) get the valued experience of mountain-climbing without the potential risk of a fatal accident.

Further, that we have new and interesting obligations as a result of intimate relationships is not enough for these relationships to be counted as interfering arbitrarily or unjustly with our self-direction, for just the same reasons that any kind of obligationgenerating relationship need not be interpreted as constitutive of heteronomy - autarchy and autonomy are not equivalent (similarly, we need not think that, say, the value of freedom is solely or best understood as unrestricted choosing).

Finally, that someone could cause us suffering or pain in an arbitrary or unjust way is not the same thing as our being structurally vulnerable to this injustice (unless there are independent relations which, for example, leave us defenceless against abusive partners). Apart from the observation that an abusive relationship is of a different kind than a loving relationship, we can add that the potential to be hurt by another is not simply equivalent to that other being in a position of domination; to put it in slightly sloganeering terms, it is 
impossible to be sure that no-one will ever try to hurt me, but possible to be fairly sure that they won't get to try it twice.

It is worth, at this point, making the parallels between the relationship and workplace (non) domination cases as clear as possible with one final comparison. Since Alice and Bryony are already to hand, let's heartlessly doom their relationship and specify that Alice is now in a new, healthy relationship while Bryony is in a new, dysfunctional relationship. Our parallel workers are the newcomers Cat and Dee; Cat has a job with fairly strong union protections, while Dee works for a union-busting industrialist.

Alice may very well be hurt by her new partner without there being any blame attached to that partner; that is, as we have seen, simply a requirement of these kinds of activities. If the end of the relationship wouldn't hurt, then it doesn't seem that Alice values the relationship at all. Similarly, Cat might lose her job, or realise that she'll never attain the kind of professional status that she desires - and again, these seem like unproblematic (though unpleasant) conceptual corollaries of pursuing a valued job. In order to win, it must be possible to lose. Further, both Alice and Cat may experience harms that are problematic in the relevant sense; that is, injustices and other moral wrongs. Alice's partner might demand an unattainable amount of attention or care and use emotional manipulation to weight her demands; Cat's colleagues or boss might present her with an unreasonable workload and make dark intimations about job losses falling on those who are not part of the work "in group". In both of these cases, we have seen, there are several levels of recourse. Alice can, at the first, upbraid her partner and point out the unacceptability of emotional blackmail; Cat can call on her union to support her in challenging this coercive attempt. Here, we would hope, the unreasonable demands cease. In a healthy relationship, being called out by your partner(s) for acting wrongly means that you stop acting like that; in a non-dominating workplace, being told that you're not allowed to do what you're trying to do to your employees or your colleagues means that you stop trying.

If it comes to pass that Alice or Cat make such requests and are ignored, then they can also simply remove themselves from the situation. Again, it will doubtless be painful in various ways, but nothing forces or pressures either of them to stay save what they themselves value. That is, Alice must decide whether she values her relationship enough to tolerate this kind of emotional violence, and Cat whether she values the job enough to put up with workplace bullying; so long as neither of them are vulnerable in the sense of being forced to choose between carrying on or homelessness, penury, public humiliation or any one of a thousand intolerably bad outcomes (and, note, outcomes that are in no way conceptually required by intimate relationships or by employment relations), then they are not dominated.

Contrast this with Bryony and Dee. Bryony's pointing out that her partner is behaving badly is not going to change anything, and may well make matters worse; what decides whether she stays or leaves is not, primarily, how much she values the relationship but whether her ending it will catalyse further immorality from her abusive partner. Of course, the bald option is there - we have no reason to think that Bryony has become incapable of standing up for herself or reasoning clearly - but it is an option with an appalling cost attached to it. Similarly, Dee does not realistically choose between fighting her corner or launching a case for constructive dismissal and leaving as Cat may choose, but rather between continuing to work in oppressive conditions and being threatened by strikebreakers, or risking starvation, and so on. In other words, both Bryony and Dee are dominated; the structures they stand in make it ruinously difficult for them to pursue their 
own values against the whim of others. It is particularly notable, as will be re-emphasised in my conclusion, that changing the background conditions but leaving the specific cases the same gives us a radically different outcome: Bryony would be much less vulnerable, dysfunctional relationship or not, if she could bail out of that relationship without undue risk of harm, and Dee would be less vulnerable if she lived in a society with (say) adequate unemployment benefit.

In both pairs of cases, what renders us dominated is not the risk of any harm but of a particular kind of structural vulnerability to certain harms: it simply isn't a conceptual necessity of a relationship, unlike the risk of emotional hurt resulting from loss or failure, that we be prevented from ending it by worries of violence or starvation. Pace certain (admittedly persuasive) claims about the nature of wage labour, there is also no reason to think that such harms are risks with a logical or conceptual link to doing some or other job.

So much, then, for the objection that valuing non-vulnerability (for example, as a component of autonomy) requires an unpleasantly a- or anti-social account of intimate relationships. We can be vulnerable in, and dominated as a result of, interpersonal relationships, but the requirements of (non-dysfunctional) intimacy are not in themselves hostile to non-vulnerability - and as I have suggested, may very well be a vital constituent of autonomy.

\section{Intimacy, Non-Domination and Freedom}

The focus of this paper has been on the apparent problem of intimacy for autonomy, but it is obvious that - given my claim that the concern is one of domination - the same or a very similar problem will crop up for anyone concerned with domination in other realms of political philosophy. In particular, it seems likely that an account of freedom as nondomination will have to deal with precisely this worry: if Bryony stands in dominating (or potentially dominating) relations to Alice, then the relationship has made Alice less free. Given that apparent parallel, and given the importance of a Pettit-influenced view of structural vectors of domination to the argument in this paper, it seems worth briefly sketching how I think the problem would play out for Pettitian conceptions of freedom.

Just as autonomy theorists should be wary of the implication that relationships make us less autonomous, an account of freedom which suggests that intimacy makes us less free seems unlikely to appeal to many (particularly given that accounts of freedom as nondomination are almost definitionally committed to rejecting the individualistic claim that we are free simply insofar as we are not interfered with). Of course, as mentioned earlier, somebody following the line that non-domination consists in institutional protection against domination could plausibly just assert that all this amounted to was an observation that political freedom may not equate to happiness or personal fulfilment.

Such a response strikes me as mistaken on two points. Firstly, it would be very odd if we should have an account of freedom as non-domination which largely ignores the effective end of the formal-effective distinction; if somebody has legal recourse against arbitrary interference by another, but could not practicably take that recourse, I cannot see that they are not dominated. Given this, and given any familiar case of domination in actual relationships (such as domestic abuse in a society with laws against it but no particular inclination to enforce those laws), arguing that we ought not to worry about inter-personal domination seems directly contrary to the republican intuition about freedom. 
Secondly, it seems to clash with Pettit's own later views, where he explicitly considers domination in intimate relationships, and argues that in a sexist society, "husbands will enjoy such power over their spouses". ${ }^{26}$ It is not wholly clear to me whether he thinks of political freedom as something that we may enjoy while being dominated in other realms, or whether political freedom is simply constituted by our being by design free from domination in general, although the latter is suggested by the discussion of nondomination as a political ideal. ${ }^{27}$ In either case, it is clear that he is concerned with worries of inter-personal domination, and as such the worry I have raised in this paper should worry anyone sympathetic to freedom as non-domination. It is, I think, defused the same way that the problem for autonomy is defused - but, given what I suggest in the conclusion, it is faced with precisely the same dispiriting trouble with regards to actuallyextant structures.

\section{Conclusion}

None of the foregoing arguments, of course, make the end of an intimate relationship any less painful. That something is, in general, a valuable pursuit does not guarantee that we will value or even wish to tolerate every aspect and possible outcome of that pursuit. Further, it seems plausible that severe enough suffering can then render an agent nonautonomous. Someone psychologically laid low to the extent that they can no longer function or pursue their life goals may fail the preconditions for autonomy.

But this is true of many pursuits: the mountain climber who takes a critical fall, the paramedic who sees a horrifying accident, and many others may all be affected such that they become less autonomous, without this implying that the relations themselves (that is, those relations which allow and/or constitute being a climber, paramedic etc) are hostile to autonomy. Ours is an unhappy world filled with damaged inhabitants, and once we accept that existence more or less inevitably contains harm then the possibility of suffering particular harms as a result of standing in particular relations cannot, by itself, make those relations autonomy-hostile.

There is one vital note of caution to be sounded. While I have argued that intimate relationships are non-dominating and ultimately very valuable, this is not to be taken as a blanket endorsement of any close relationship, nor as a further retread of the unconvincing public-private separation. If anything, the view I have put forward here militates in the other direction. Quite apart from the more obvious cases of dysfunctional relationships, the endemic examples of domestic abuse and exploitation, the fact that our vulnerability is dependent on relations or structures outwith our particular interpersonal relationships means that an unjust society renders many (apparently or putatively) valuable and happy relationships potentially dominating in the final analysis. For example, given the patriarchal and misogynistic norms of the UK, it is almost always going to be the case that a woman in a heterosexual couple has significantly less recourse against emotional or physical violence than a (cisgendered) man does; even when both agents are genuinely committed to each other, unselfconsciously concerned with the other's welfare and so on, the powerimbalanced structures of society mean that one still stands in a position of domination over the other.

So, while my argument here has largely been optimistic - in an ideal world, we can value both freedom and intimacy perfectly well, and a commitment to autonomy need not 
involve taking to the hills with a rifle - its implications for our non-ideal world are deeply pessimistic. The dysfunction of our society renders our relationships dysfunctional unless and until that society changes: background conditions of injustice turn intimacy into a mechanism for reinforcing and reproducing oppression. If we can wrestle anything positive out of the observation, it is that this should serve as yet another motivation for challenging the structures and norms we find ourselves embedded in.

Even more alarmingly for philosophers, careful reflection butters few parsnips here. I may, perhaps, be able to take steps to recognise and attempt to curb some of the worst effects of my dominating position through sober consideration of the various social and economic relations I stand in, but it remains the case that - structurally speaking - this just makes me the benevolent slave-owner, disinclined to leverage his dominance yet still dominant for all that. The master-slave relationship does not seem like one we should replicate in our intimate lives, absent certain kinks; and I have yet to meet a sub who gets their kicks from being seen as worthless or not deserving of respect by society at large. ${ }^{28}$

\section{NOTES}

1 See, among others, Friedman, Autonomy, Gender, Politics (Oxford University Press: Oxford, 1996); Meyers, 'Decentralizing Autonomy: Five Faces of Selfhood' in Christman \& Anderson (eds.), Autonomy and the Challenges to Liberalism (Cambridge University Press: Cambridge, 2005), pp27-55; Oshana, Personal Autonomy in Society (Ashgate: Aldershot, 2006);

2 See (again among others) Friedman, Autonomy and the Split-Level Self', Southern Journal of Philosophy 24 No. 1 (1986), pp19-35; Oshana, op. cit.; and, for empirical data, Chapter 3 of Smith (ed.), Osborne, Lau and Britton, Home Office Statistical Bulletin 'Homicides, Firearm Offences and Intimate Violence: Supplementary Volume 2 to Crime in England and Wales 2010/11' (online at https://www.gov.uk/government/uploads/system/uploads/attachment_data/file/116483/hosb0212.pdf)

3 Friedman, op. cit. p129.

4 For a fairly recent argument of the former type, see Smith, 'Egoistic Friendship', American Philosophical Quarterly (Vol. 42, No. 2, 2005), pp263-277. The trouble arising from the latter, pluralist thought is not that pluralism necessarily suggests that autonomy and intimacy are incompatible, but that it gives us no strong reason to doubt it, and so we must find independent arguments. See Chapter 14 of Raz, The Morality of Freedom (OUP: New York, 1986) for one example of how valuing autonomy may be consistent with valuing other ideals which are themselves (taken to be) inconsistent with autonomy

5 Oshana, op. cit. A roughly similar thesis, that our social context "puts agents' autonomy status outside their complete control”, can be found in Sperry, 'Autonomy Luck: Relational Autonomy, Moral Luck and Social Oppression', Social Philosophy Today, 25 (2009), pp165-178. While the argument is still very much live, and I am grateful to a reviewer for pointing out that my intuitions are far from universally felt, I think the relational account presumed in this paper is at least in fairly good company.

6 Meyers, 'Intersectional Identity and the Authentic Self' in Mackenzie \& Stoljar (eds.) Relational Autonomy (OUP: New York, 2000), pp151-180. There are interesting questions about the extent to which we should read Meyers as claiming that oppression need not limit an agent's autonomy, rather than claiming that members of oppressed groups can have access to information which makes them better judges of what is necessary for their autonomy - but they are orthogonal to my main task here.

7 Most commonly associated with Pettit's republicanism, non-domination is also a key part of many contemporary autonomy theories. See Philip Pettit, Republicanism: A Theory of Freedom and Government (OUP: New York, 1997) for the former and Oshana (op. cit.) for the latter. Although she does not use the term, something very like non-domination obviously plays a role in Marilyn Friedman's conception of autonomy; see Friedman, op. cit, particularly Ch. 4, 'Autonomy and Social Relationships'. Although Friedman does in fact speak of agents as being "more autonomous the more she can succeed in pursuing her concerns despite resistance" (p13), it is in the context of "resilience in the face of at least minimal obstacles" - I take it from this that the importance to autonomy of 
overcoming obstacles is primarily psychological stability or coherence, rather than implying that the more one has to struggle, the more autonomous one is.

8 A very odd implication indeed, and one which I would like to thank an anonymous reviewer for pointing out, this should also serve as a kind of early warning that we ought to reject the idea of relationships being necessarily dominating - although, of course, there is still further work required to explain and justify such a rejection.

9 Pettit, op. cit., pp22-24.

10 It is worth re-stating here that while on my view domination is simply incompatible with maximal autonomy (though being dominated may not disbar an agent from more limited autonomy and is not a necessary defeater of authentic/instrumentally rational/reflectively endorsed/etc choices), there is no reason for domination worries to be unique to relational accounts. It seems clear that domination will tend to have an adverse material effect on one's pursuit of deeply-held values and may also harm one's ability to form reflectively or procedurally independent desires, to give two examples which will be relevant for non-relational autonomy theorists. As such, we can still say that domination is always a bad thing for autonomy without being committed to either a relational view or the view that dominated agents cannot be autonomous. If we imagine two agents, identical in every way save that one of them is dominated, the claim that the non-dominated agent is more autonomous, or their autonomy is at less risk, or that they do not have to work excessively to preserve their self-conception (and so on) seems plausible to me.

11 For a fuller picture of his account of non-domination, see Pettit, op. cit., and Pettit, 'Freedom as Anti-Power', Ethics 106, 3 (1996), pp576-604.

12 Unless, perhaps, we mean arbitrary in the sense used when describing some action or theory as making morally arbitrary distinctions, where the arbitrariness is more akin to fixing on morally irrelevant factors than "just plumping" - non-domination as "freedom from arbitrary interference" seems sufficient if it is understood as freedom from morally arbitrary interference.

13 Since there are plausible test cases where an agent is dominated despite having legal recourse against the dominator (for example, when one colleague could notionally bring an industrial tribunal against another), I tend to think that we should be concerned with legal domination only as part of social domination anyhow, but that's a somewhat different matter.

14 Oshana, op. cit., p86.

15 Friedman (op. cit., pp121-126 ) considers precisely this problem, and provides a fuller list of the kinds of (autonomy-minded) worries we might have about intimate relationships. See also David Owens, Shaping the Normative Landscape (OUP: Oxford, 2012), particularly chapter 4, 'Obligations and Involvement', and Thomas Scanlon, What We Owe to Each Other (Harvard University Press: Massachusetts, 1998).

16 Strictly speaking, in fact, the critic has attacked this claim - I am again grateful to a reviewer for this objection.

17 Ayn Rand's claim that the free and ethical agent "honors scrupulously the obligations that he has chosen", for example, makes such a view fairly explicit; see Rand Philosophy: Who Needs It (Bobbs-Merril Company: Indianapolis), p121. On a similar note, Tara Smith (op. cit.) addresses exactly the question of job versus relationships, arguing that the only reason we would have not to prevail upon or manipulate a friend into not leaving is the risk of damaging their value to us; "it is unrealistic to expect to reap all the same value from a person whose means of generating value have been thrown off-track" (p271). In short, loving someone is only valuable (or rational, as the Objectivists would have it) insofar as it is in our interests to do so, or it furthers our general life plan to do so. This carries the clear implication that we can and ought reject obligations of intimacy which we have not explicitly agreed to, perhaps unless we feel that fulfilling the obligation would be to our advantage.

18 "It is one thing to avoid the state of moral overcommitment which, like literal indebtedness, can lead to its own kind of bankruptcy, but quite another to arrange one's life deliberately to minimize involvement with, and therefore commitment to, other persons on the grounds that commitment per se diminishes autonomy [emphasis mine]. It would take a misanthrope or an egoist (though perhaps a principled one) even to aim at such an ideal." Joel Feinberg, 'Autonomy' in John Christman (ed), The Inner Citadel: Essays on Individual Autonomy (OUP: Oxford, 1989), p44

19 Jay Wallace, 'Duties of Love', Proceedings of the Aristotelian Society, Supplementary Vol. LXXXVI (2012), p189.

20 I can, I think, remain neutral on whether this obligation is a derivative or, as Wallace would have it, non-derivative and sui generis 'duty of love' - whatever its ultimate ground, we can surely agree that being bound by a duty of comfort is just part of what it is to be in an intimate relationship with somebody (I am grateful to a conference attendee for pointing out that much in the domination debate may turn on the conception of love one uses, and as such have attempted to restrict myself to talking about intimate relationships rather than love).

21 Or that I authentically desire such obligations and my pursuit of these desires constitutes my autonomy, etc; as it happens, I think a relational analysis of autonomy fits best with the thoughts about domination given here, but it is not too difficult to reconceptualise the conclusion in terms that fit with competing autonomy theories, and in any case that debate is not the prime matter at hand.

22 Wallace, op. cit.

23 There is a much wider worry about consent and its scope as a normative transformer to be addressed here, but not one that can be settled in this paper. For my purposes, it is only necessary that we consent to the obligations of relationships more or less analogously to the way we consent to other social or economic obligations. Bluntly, whether or not we meaningfully consent to any of these things is - for the moment - a less important question than 
whether whether obligations of intimate relationships are a special case consent-wise, and it seems to me that they aren't.

24 As Owens (2012, p103) says, "the bonds of friendship depend on its being chosen to at least some extent...the closeness of those bonds is a function of [among others] how willingly the friendship is created and sustained", and we would not claim that a stalker's victim was willingly sustaining a friendship or even a relationship. Similarly, even a friendship or intimate relationship that was started and sustained willingly cannot endorse some kinds of actions. To give a blunt example, no-one can demand rightfully that I kill myself to prove my love, or (putting it the other way around) claim that my refusal to do so marks a breach of friendship or relationship obligations.

25 The other obvious problem is one where I am forced to stay in a relationship not because of psychological but material coercion - the situation experienced by abused partners who literally have nowhere to go, or where leaving the relationship would be social suicide, and so on. Here, again, the problem is not confined to the relationship, but involves the other relations I stand in. The fact that the depicted society will fail to defend me, or will enable abuse, is already enough to fail the non-vulnerability requirement, and is what explains (or, as I would have it, constitutes) the agent's heteronomy in such cases.

26 Pettit 1997, p61.

27 Pettit op. cit., pp92-97.

28 This article owes much to feedback from Dr. Ben Colburn, questions and objections from attendees at the MANCEPT workshops in September 2016, and several anonymous reviews. The work was supported by a grant from the Carnegie Trust for the Universities of Scotland. 